\title{
Avaliação do conhecimento pré/pós intervenção educativa sobre reanimação cardiopulmonar em estudantes de ciências da saúde
}

\author{
Evaluation of pre/post educational intervention knowledge about cardiopulmonary \\ resuscitation in students of health sciences
}
Evaluación de conocimientos antes/después de la intervención educativa sobre reanimación cardiopulmonar en estudiantes de ciencias de la salud

Tamíris Augusto Marinho ${ }^{1}$, Charlise Fortunato Pedroso ${ }^{1}$, Thaís Augusto Marinho ${ }^{1 *}$, Ingrid Aline de Jesus Gonçalves ${ }^{1}$, Lyriane Apolinário de Araújoํㅜㄹ Thays Angélica de Pinho Santos ${ }^{1}$, Patrícia Silva Nunes ${ }^{1}$.

\section{RESUMO}

Objetivo: Avaliar o conhecimento teórico/prático sobre reanimação cardiopulmonar em estudantes de ciências da saúde pré/pós intervenção educativa. Métodos: Trata-se de estudo quase-experimental, do tipo antes-depois com abordagem quantitativa. Resultados: Na distribuição por cursos, $43,9 \%$ pertenciam ao curso Técnico de Enfermagem; 39,4\% Análises Clínicas; 12,1\% Nutrição e Dietética e 4,5\% Vigilância em Saúde. Após intervenção educativa, o componente parada cardiorrespiratória apresentou em $50,0 \%$ dos itens aumento significativo de acertos, no componente desfibrilador externo automático todos os itens mostraram aumento significativo e no componente reanimação cardiopulmonar seis dos 10 itens tiveram significância nos acertos. No componente 4, execução prática, em todos os questionamentos houve melhora significativa. $\mathrm{Na}$ análise do efeito, verificou-se aumento significativo em todos os componentes: Teoria-parada cardiorrespiratória (72,1\% para 82,7\%), Teoria-desfibrilador externo automático (52,5\% para 80,3\%), Teoriareanimação cardiopulmonar (60,0\% para $78,6 \%)$; Prática (15,7\% para $77,9 \%)$ e Conhecimento global $(50,1 \%$ para 79,9\%). Conclusão: O grau de conhecimento foi melhorado após intervenção educativa.

Palavras-chave: Assistência pré-hospitalar, Conhecimento, Educação em enfermagem, Estudantes de ciências da saúde, Reanimação cardiopulmonar.

\begin{abstract}
Objective: To evaluate the theoretical/practical knowledge about cardiopulmonary resuscitation in health science students pre/post educational intervention. Methods: Quasi-experimental study, of the before-after type with a quantitative approach. Results: In the distribution by courses, $43.9 \%$ belonged to the Nursing Technician course; $39.4 \%$ Clinical Analyzes; $12.1 \%$ Nutrition and Dietetics and 4.5\% Health Surveillance. After educational intervention, the cardiorespiratory arrest component showed a significant increase in correct answers in $50.0 \%$ of the items, in the automatic external defibrillator component all items showed a significant increase and in the cardiopulmonary resuscitation component six of the 10 items had significance in the correct answers. In component 4 practical execution, there was a significant improvement in all questions. In the analysis of the effect, there was a significant increase in all components: Theory-cardiorespiratory arrest (72.1\% to $82.7 \%)$, Theory-automatic external defibrillator $(52.5 \%$ to $80.3 \%)$, Theory- cardiopulmonary resuscitation (60.0\% to $78.6 \%$ ); Practice (15.7\% to $77.9 \%$ ) and Global knowledge $(50.1 \%$ to $79.9 \%)$. Conclusion: The degree of knowledge was improved after educational intervention.
\end{abstract}

Keywords: Prehospital emergency care, Knowledge, Nursing education, Health occupations students, Cardiopulmonary resuscitation.

\footnotetext{
1 Instituto Federal de Educação, Ciência e Tecnologia de Goiás (IFG), Goiânia - GO.

*E-mail: thais.marinho@ifg.edu.br
} 


\section{RESUMEN}

Objetivo: Evaluar los conocimientos teórico-prácticos sobre reanimación cardiopulmonar en estudiantes de ciencias de la salud antes/después intervención educativa. Métodos: estudio cuasiexperimental, del tipo antes-después con enfoque cuantitativo. Resultados: En la distribución por cursos, el 43,9\% pertenecía al curso de Técnico en Enfermería; 39,4\% Análisis clínicos; 12,1\% Nutrición y Dietética y 4,5\% Vigilancia de la Salud. Tras la intervención educativa, el componente de parada cardiorrespiratoria mostró un aumento significativo de respuestas correctas en el $50,0 \%$ de los ítems, en el componente de desfibrilador externo automático todos los ítems mostraron un aumento significativo y en la reanimación cardiopulmonar EI componente seis de los 10 ítems tuvo importancia en las respuestas correctas. En la ejecución práctica del componente 4, hubo una mejora significativa en todas las preguntas. En el análisis del efecto, hubo un aumento significativo en todos los componentes: Teoría-parada cardiorrespiratoria $(72,1 \%$ a $82,7 \%)$, Teoríadesfibrilador externo automático (52,5\% a 80,3\%), Teoría-reanimación cardiopulmonar (60,0\% a 78,6\%) \%); Práctica $(15,7 \%$ a $77,9 \%)$ y Conocimiento global (50,1\% a 79,9\%). Conclusión: Se mejoró el grado de conocimiento tras la intervención educativa.

Palabras clave: Atención prehospitalaria, Conocimiento, Educación en enfermería, Estudiantes del área de la salud, Reanimación cardiopulmonar.

\section{INTRODUÇÃO}

Doença cardíaca isquêmica, é a principal determinante da parada cardiorrespiratória (PCR), liderando as causas de óbitos no mundo e no Brasil (BERNOCHE C, et al., 2019; MONSIEURS KG, et al., 2015). Estimase, anualmente, 200 mil vítimas de PCR, sendo metade dos casos ocorrendo em ambiente hospitalar e a outra metade em ambientes extra-hospitalares (GONZALEZ MM, et al., 2013). O aumento nos índices de mortalidade por acidentes, violência física e urgências/emergências clínicas tornaram a PCR importante problema de saúde pública global (AHA, 2015).

American Heart Association (AHA) propõe diretrizes para realização da RCP baseada em evidências científicas. Nessas diretrizes enfatiza-se Suporte Básico de Vida (SBV) e qualidade da RCP para socorristas leigos e profissionais de saúde seguindo cadeias de sobrevivência padronizadas (AHA, 2015; AHA, 2019).

Contudo, eventos adversos ocorridos em atendimentos de profissionais que atuam em urgência/emergência têm sido observados e relacionados à falta de qualificação profissional e ausência de educação continuada. A principal dificuldade enfrentada segundo relato desses profissionais, apresentada em uma revisão de literatura, é a falta de capacitação contínua. Tal dificuldade pode levar a desmotivação, comprometendo a qualidade da assistência prestada (SILVA WM, et al., 2020).

Em estudo realizado em São Paulo, Brasil, com os enfermeiros que atuam em situações de PCR, 77,6\% afirmaram que a falta de relação harmoniosa da equipe, a qual poderia ser praticada em treinamentos, interfere negativamente na assistência prestada às vítimas em PCR (CITOLINO FILHO, et al., 2015). Portanto, o determinante mais importante para a sobrevivência da vítima, a uma parada cardíaca, é a presença de socorristas treinados, dispostos e equipados (YAN S, et al., 2020).

O International Liaison Committee on Resuscitation destaca intervenções educacionais para solucionar problemas na prática da RCP com abordagem baseada em equipe e tecnologias de simulação em ambiente de aprendizado realístico e seguro (ONAN A, et al., 2017). Assim, treinamentos em RCP devem ser acessíveis e democráticos, possibilitando aos indivíduos, inclusive estudantes da área da saúde, atuarem com segurança em situações de emergência (FOWLER R, et al., 2017).

O artigo tem como objetivo avaliar o conhecimento teórico e prático sobre RCP em estudantes de ciências da saúde, pré e pós uma intervenção educativa.

\section{MÉTODOS}

O presente estudo foi aprovado pelo Comitê de Ética em Pesquisa, via Plataforma Brasil, parecer no CAAE: 74495317.0.0000.8082, e foi conduzida respeitando os aspectos éticos, segundo as normas da Resolução 466/2012 do Conselho Nacional de Saúde. 
Os discentes foram convidados a participar da pesquisa e orientados quanto à importância do estudo, objetivos, participação voluntária, anonimato e demais aspectos. Após anuência verbal quanto à participação no estudo, foi assinado o Termo de Consentimento Livre e Esclarecido (TCLE). Os responsáveis legais dos discentes menores de 18 anos foram orientados quanto aos aspectos supracitados e após autorização, foi requerido à assinatura do TCLE e do Termo de Assentimento (TA) do menor.

Trata-se de um estudo quase-experimental, do tipo antes-depois com abordagem quantitativa. A manipulação da variável independente (intervenção educativa téorico-prática) ocorreu sem designação de um grupo controle ou randomização dos participantes. Em estudos do tipo antes-depois, as aferições são feitas antes e depois de cada participante ser submetido à intervenção. Assim, cada estudante serviu como seu próprio controle para a avaliação dos efeitos da intervenção educativa.

A condução do estudo foi feita em uma instituição de ensino federal, no período de abril e maio de 2018. O estudo foi realizado e relatado em consonância com as recomendações do "Strengthening the Reporting of Observational studies in Epidemiology (STROBE STATEMENT), adaptado em suas extensões (Reporting Guidelines for Health Care Simulation Researc and Reporting criteria for descriptions of training interventions in healthcare)" disponível em https://www.equator-network.org.

Fizeram parte do estudo discentes da área da saúde de uma instituição federal de ensino da região metropolitana de Goiânia que oferece cursos na área da saúde, na modalidade técnico integrado ao ensino médio em tempo integral em Análises Clínicas, Nutrição e Dietética, Vigilância em Saúde, e técnico integrado de Enfermagem, na modalidade de Educação de Jovens e Adultos (EJA). O recrutamento ocorreu com chamada pública em mural escolar e abertura de inscrição em dia e horário pré-determinado até o limite de 70 vagas, divididas em 2 turmas. Para inscrição no estudo foram considerados aos seguintes critérios de elegibilidade: estar matriculado em curso da área da saúde, comparecer no campus nos dias das coletas de dados e cumprirem ao menos $80 \%$ da carga horária estabelecida para intervenção educativa sobre RCP.

O estudo foi conduzido seguindo sequencialmente três etapas, com intervalo semanal entre cada uma delas, a saber: 1) encontro presencial com avaliação do conhecimento pré intervenção - teórico e prático; 2) aplicação da intervenção educativa sobre RCP - teórica e prática; 3) encontro presencial com avaliação do conhecimento teórico e prático pós intervenção.

A coleta de dados ocorreu em dois momentos, pré e pós intervenção educativa. Para isso foram utilizados questionários padronizados em dois formatos: (i) questionário autoaplicável preenchido pelos participantes (avaliação do conhecimento teórico) e (ii) questionário de avaliação prática preenchido por três avaliadores com expertise na temática, onde foram avaliadas as etapas de RCP de alta qualidade, por meio de simulação realística executada por cada participante.

O questionário autoaplicável era composto por questões sociodemográficas, e referentes às habilidades e conhecimentos sobre RCP. Já o questionário para avaliação prática foi estruturado em check-list simples (Sim ou Não) para conferência da execução das etapas preconizadas para RCP. Os questionários foram elaborados por pesquisadores com expertise na temática tendo como base as recomendações técnicas do Guideline da American Heart Association (AHA, 2015).

Os dados foram analisados no software estatístico R. Inicialmente, realizou-se análise descritiva das características sociodemográficas e acadêmicas dos discentes; variáveis quantitativas foram apresentadas como média e desvio padrão (DP) e as qualitativas como frequência absoluta (n) e relativa (\%).

Para análise do nível de conhecimento, foram atribuídas as nomenclaturas: componente 1 (conhecimento teórico relativo a PCR), componente 2 (conhecimento teórico relativo ao DEA), componente 3 (conhecimento teórico relativo a técnica de RCP), componente 4 (aplicação do conhecimento teórico e execução da prática) e componente global (média dos 4 componentes). Calculou-se o nível de conhecimento em cada componente, em percentual (\%), pela soma dos acertos de cada participante, dividido pelo total de itens de cada componente, $x$ 100. O componente global foi calculado pela média aritmética dos quatro componentes principais. Assim, o nível de conhecimento de cada componente poderia variar de 0 (menor nível de conhecimento) a 100\% (maior nível de conhecimento). 
Os itens do conhecimento foram descritos como frequência absoluta, relativa e respectivo intervalo de confiança de $95 \%$. O nível de conhecimento de cada componente e global foram descritos como média e IC95\% da média.

Para verificar diferenças significativas nas proporções dos itens de cada componente pré e pós intervenção educativa sobre RCP foi utilizado o teste de McNemar. O tamanho do efeito da diferença foi estimado pelo Cohen'g. Valores de Cohen's $g$ de 0,05-0,15 indicam efeito pequeno, 0,15-0,24 efeito médio e $>0,25$ efeito grande.

Para verificar as diferenças nos escores médios dos componentes pré e pós intervenção educativa sobre RCP foi utilizado o teste t de Student para amostras pareadas. O tamanho do efeito da diferença foi estimado pelo Cohen'd. Valores de Cohen's d de 0,00-0,20 indicam efeito pequeno, 0,21-0,79 efeito médio e $>0,80$ efeito grande. Em todas as análises, valores de $p<0,05$ foram considerados estatisticamente significantes.

\section{RESULTADOS}

Foram inscritos na pesquisa 70 estudantes, dos quais 66 atenderam aos critérios de inclusão e 04 foram excluídos por não atingir a carga horária mínima no momento da intervenção educativa. A Tabela 1 mostra as características sociodemográficas e acadêmicas dos discentes analisados. A média de idade foi de 23,5 anos $(\mathrm{DP}=11,3)$ e a da renda familiar foi de $\mathrm{R} \$ 2.860,0(\mathrm{DP}=2.570,9)$. A maioria era do sexo feminino $(86,4 \%)$, sem cônjuge $(75,3 \%)$ e da raça/cor autorreferida como parda (53,0\%). Na distribuição por cursos, 43,9\% eram do curso Técnico de Enfermagem, 39,4\% Análises Clínicas, 12,1\% Nutrição e Dietética e 4,5\% Vigilância em Saúde. Quanto ao período, a metade (50,0\%) estava no segundo período.

Tabela 1 - Características sociodemográficas e acadêmicas dos discentes da área da saúde, N=66. Goiânia - GO, 2021.

\begin{tabular}{lcc}
\hline Características & \multicolumn{2}{c}{$23,5(11,3)$} \\
\hline Idade (anos), média (DP) & $2.860,0$ & $(2.570,9)$ \\
\hline Renda familiar (R\$), média (DP) & $\mathbf{N}$ & $(\%)$ \\
\hline Sexo & 57 & 86,4 \\
\hline Masculino & 9 & 13,6 \\
Feminino & $\mathbf{N}$ & $\mathbf{( \% )}$ \\
\hline Estado conjugal & 50 & 75,3 \\
\hline Sem cônjuge & 16 & 24,2 \\
Com cônjuge & $\mathbf{N}$ & $(\%)$ \\
\hline Raça/cor da pele & 15 & 22,7 \\
\hline Branca & 35 & 53,0 \\
Parda & 11 & 16,7 \\
Preta & 5 & 7,6 \\
Outra (amarela ou indígena) & $\mathbf{N}$ & $(\%)$ \\
\hline Curso & 26 & 39,4 \\
\hline Análises clínicas & 8 & 12,1 \\
Nutrição e dietética & 3 & 4,5 \\
Vigilância em saúde & 29 & 43,9 \\
Enfermagem & $\mathbf{N}$ & $(\%)$ \\
\hline Período & 33 & 50,0 \\
\hline Segundo & 17 & 25,8 \\
Terceiro & 16 & 24,2 \\
Quarto ou mais & &
\end{tabular}

Legenda: $\mathrm{R} \$=$ Reais; $\mathrm{DP}=$ Desvio padrão.

Fonte: Marinho TA, et al., 2021. 
Antes de analisar o conhecimento dos discentes, foram realizadas três perguntas gerais sobre o interesse em trabalhar em urgência e emergência, antecedente de capacitação e conhecimento sobre as diretrizes da AHA. Do total, $87,9 \%$ dos discentes relataram que possuem interesse em trabalhar com urgência e emergência, 97,0\% relataram não ter participado de capacitações sobre urgência ou emergência e 97,0\% também afirmaram não ter conhecimento sobre as diretrizes da AHA (dado não apresentado em tabela).

A Tabela 2 mostra o efeito da intervenção sobre o componente 1 dos discentes. Dos 10 itens analisados, em cinco $(50,0 \%)$ verificou aumento estatisticamente significante na proporção de acertos pelos discentes.

Tabela 2 - Análise do efeito da intervenção educativa sobre RCP nos itens do componente 1 dos discentes da área da saúde, N=66. Goiânia - GO, 2021.

\begin{tabular}{|c|c|c|c|c|c|c|}
\hline \multirow{2}{*}{ Itens $^{\dagger}$} & \multicolumn{2}{|r|}{ Pré } & \multicolumn{2}{|r|}{ Pós } & \multirow[b]{2}{*}{$p^{\star}$} & \multirow[b]{2}{*}{ Cohen'g } \\
\hline & $\mathbf{n}$ & $\%$ (IC95\%) & $\mathbf{N}$ & $\%$ (IC95\%) & & \\
\hline A PCR é o critério de morte encefálica & 52 & $\begin{array}{c}78,8 \\
(67,5-86,9) \\
\end{array}$ & 48 & $\begin{array}{c}72,7 \\
(61,0-82,0) \\
\end{array}$ & 0,454 & 0,125 \\
\hline $\begin{array}{c}\text { Somente um profissional da saúde é } \\
\text { capaz de reverter a PCR }\end{array}$ & 46 & $\begin{array}{c}69,7 \\
(57,8-79,5)\end{array}$ & 54 & $\begin{array}{c}81,8 \\
(70,9-89,3)\end{array}$ & 0,077 & 0,240 \\
\hline $\begin{array}{l}\text { A identificação é feita avaliando se a } \\
\text { vítima responde, ausência de pulso e } \\
\text { respiração em } 10 \text { segundos }\end{array}$ & 55 & $\begin{array}{c}83,3 \\
(72,6-90,4)\end{array}$ & 65 & $\begin{array}{c}98,5 \\
(91,9-99,7)\end{array}$ & 0,002 & 0,500 \\
\hline $\begin{array}{l}\text { A frequência de compressão é de } 90- \\
100 \text { compressões/min }\end{array}$ & 21 & $\begin{array}{c}31,8 \\
(21,9-43,8)\end{array}$ & 52 & $\begin{array}{c}78,8 \\
(67,5-86,9)\end{array}$ & $<0,001$ & 0,419 \\
\hline $\begin{array}{l}\text { A profundidade da compressão é de no } \\
\text { mínimo } 5 \mathrm{~cm} \text { ( } 02 \text { polegadas) e não } \\
\text { exceder } 6 \mathrm{~cm} \text { (2,4 polegadas) }\end{array}$ & 49 & $\begin{array}{c}74,2 \\
(62,3-86,3)\end{array}$ & 58 & $\begin{array}{c}89,4 \\
(77,9-93,7)\end{array}$ & 0,002 & 0,500 \\
\hline $\begin{array}{c}\text { As duas mãos precisam estar } \\
\text { sobrepostas sobre a metade inferior do } \\
\text { osso esterno }\end{array}$ & 58 & $\begin{array}{c}87,9 \\
(77,9-93,7)\end{array}$ & 65 & $\begin{array}{c}98,5 \\
(91,9-99,7)\end{array}$ & 0,016 & 0,500 \\
\hline $\begin{array}{l}\text { Não é necessário esperar o retorno do } \\
\text { tórax entre compressões }\end{array}$ & 54 & $\begin{array}{c}81,8 \\
(70,9-89,3)\end{array}$ & 60 & $\begin{array}{c}90,9 \\
(80,6-95,6)\end{array}$ & 0,210 & 0,189 \\
\hline $\begin{array}{l}\text { É importante ter um amplo intervalo } \\
\text { entre as compressões para o socorrista } \\
\text { recuperar o fôlego }\end{array}$ & 50 & $\begin{array}{c}75,8 \\
(64,2-84,5)\end{array}$ & 62 & $\begin{array}{c}93,9 \\
(85,4-97,2)\end{array}$ & 0,004 & 0,375 \\
\hline $\begin{array}{c}\text { A relação compressão sem via aérea } \\
\text { avançada é igual com } 1 \text { ou } 2 \\
\text { socorristas, sendo } 30 \text { compressões para } \\
02 \text { ventilações }\end{array}$ & 43 & $\begin{array}{c}65,2 \\
(53,1-75,2)\end{array}$ & 45 & $\begin{array}{c}68,2 \\
(56,2-78,2)\end{array}$ & 0,552 & 0,033 \\
\hline $\begin{array}{c}\text { A relação compressão com via aérea } \\
\text { avançada é: compressões contínuas a } \\
\text { uma frequência de } 100 \text { a } 120 / \text { min e } 01 \\
\text { ventilação a cada } 06 \text { segundos ( } 10 \\
\text { respirações/min.) }\end{array}$ & 48 & $\begin{array}{c}72,7 \\
(61,0-82,0)\end{array}$ & 36 & $\begin{array}{c}54,5 \\
(42,6-66,0)\end{array}$ & 0,052 & 0,188 \\
\hline
\end{tabular}

Legenda: IC95\%=Intervalo de Confiança de 95\%; PCR=Parada Cardiorrespiratória; min=minuto, *Teste de McNemar, †Representa a proporção de acertos dos discentes (\%) e IC95\%.

Fonte: Marinho TA, et al., 2021.

A Tabela 3 mostra o efeito da intervenção sobre os componentes 2 e 3 . Com relação ao componente 2, todos os três itens apresentaram aumento significativo na proporção de acertos dos discentes após a intervenção. Quanto ao componente 3 seis $(60,0 \%)$ dos 10 itens analisados mostraram aumento significativo na proporção de acertos dos discentes. 
Tabela 3 - Análise do efeito da intervenção educativa sobre RCP nos itens dos componentes 2 e 3 dos discentes da área da saúde, N=66. Goiânia - GO, 2021.

\begin{tabular}{|c|c|c|c|c|c|c|}
\hline \multirow{2}{*}{ Itens $^{\dagger}$} & \multicolumn{2}{|r|}{ Pré } & \multicolumn{2}{|r|}{ Pós } & \multirow[b]{2}{*}{$p^{*}$} & \multirow[b]{2}{*}{ Cohen'g } \\
\hline & $\mathbf{n}$ & $\%($ (IC95\%) & $\mathbf{n}$ & $\%$ (IC95\%) & & \\
\hline \multicolumn{7}{|l|}{ DEA } \\
\hline $\begin{array}{l}\text { Recomenda-se implantar em locais } \\
\text { públicos onde haja uma probabilidade } \\
\text { relativamente alta de PCR presenciada } \\
\text { (por exemplo: aeroportos, cassinos, } \\
\text { instalações esportivas e etc }\end{array}$ & 45 & $\begin{array}{c}68,2 \\
(56,2-78,2)\end{array}$ & 63 & $\begin{array}{c}95,5 \\
(87,5-98,4)\end{array}$ & $<0,001$ & 0,500 \\
\hline $\begin{array}{l}\text { Toda PCR precisa necessariamente de } \\
\text { choque para reanimação com sucesso } \\
\text { do cliente }\end{array}$ & 54 & $\begin{array}{c}81,8 \\
(70,9-89,3)\end{array}$ & 62 & $\begin{array}{c}93,9 \\
(85,4-97,2)\end{array}$ & 0,039 & 0,333 \\
\hline $\begin{array}{l}\text { Todo socorrista leigo precisa de } \\
\text { treinamento para manusear DEA }\end{array}$ & 5 & $\begin{array}{c}7,6 \\
(3,3-16,5)\end{array}$ & 34 & $\begin{array}{c}51,5 \\
(39,7-63,2)\end{array}$ & $<0,001$ & 0,468 \\
\hline \multicolumn{7}{|l|}{ RCP } \\
\hline Reportou a ordem correta da RCP & 2 & $\begin{array}{c}3,0 \\
(0,8-10,4) \\
\end{array}$ & 35 & $\begin{array}{c}53,0 \\
(41,2-64,6) \\
\end{array}$ & $<0,001$ & 0,500 \\
\hline $\begin{array}{l}\text { O número total de compressões } \\
\text { aplicadas durante a reanimação é um } \\
\text { fator determinante importante de } \\
\text { sobrevivência em RCP }\end{array}$ & 47 & $\begin{array}{c}71,2 \\
(59,4-80,7)\end{array}$ & 62 & $\begin{array}{c}93,9 \\
(85,4-97,2)\end{array}$ & $<0,001$ & 0,441 \\
\hline $\begin{array}{c}\text { Aplicar a ventilação excessiva é } \\
\text { necessário para o retorno do cliente em } \\
\text { PCR }\end{array}$ & 33 & $\begin{array}{c}50,0 \\
(38,3-61,7)\end{array}$ & 58 & $\begin{array}{c}87,9 \\
(77,9-93,7)\end{array}$ & $<0,001$ & 0,463 \\
\hline $\begin{array}{c}\text { Não é necessário verificar a segurança } \\
\text { do local, afinal a vítima em PCR precisa } \\
\text { de assistência em caráter de } \\
\text { emergência }\end{array}$ & 37 & $\begin{array}{c}56,1 \\
(44,1-67,4)\end{array}$ & 61 & $\begin{array}{c}92,4 \\
(83,5-96,7)\end{array}$ & $<0,001$ & 0,500 \\
\hline $\begin{array}{l}\text { Caso a vítima não responda, grite por } \\
\text { ajuda para alguém próximo acionar o } \\
\text { serviço médico de emergência por } \\
\text { telefone celular (se apropriado) }\end{array}$ & 63 & $\begin{array}{c}95,5 \\
(87,5-98,4)\end{array}$ & 66 & $\begin{array}{l}100,0 \\
(94,5- \\
100,0)\end{array}$ & 0,250 & 0,178 \\
\hline $\begin{array}{l}\text { Obtenha o DEA e equipamentos de } \\
\text { emergência (ou peça alguém para fazê- } \\
\text { lo) }\end{array}$ & 26 & $\begin{array}{c}39,4 \\
(28,5-51,5)\end{array}$ & 51 & $\begin{array}{c}77,3 \\
(65,8-85,7)\end{array}$ & $<0,001$ & 0,379 \\
\hline $\begin{array}{c}\text { Caso a vítima responda e apresente } \\
\text { respiração e pulso, monitore até a } \\
\text { chegada do serviço médico de } \\
\text { emergência }\end{array}$ & 65 & $\begin{array}{c}98,5 \\
(91,9-99,7)\end{array}$ & 65 & $\begin{array}{c}98,5 \\
(91,9-99,7)\end{array}$ & 1,000 & 0,000 \\
\hline $\begin{array}{l}\text { A ventilação é mais importante que a } \\
\text { compressão na RCP }\end{array}$ & 55 & $\begin{array}{c}83,3 \\
(72,6-90,4)\end{array}$ & 63 & $\begin{array}{c}95,5 \\
(87,5-98,4)\end{array}$ & 0,039 & 0,333 \\
\hline $\begin{array}{l}\text { Caso a vítima apresente frequência } \\
\text { respiratória, não é necessário a } \\
\text { manobra de extensão da mandíbula }\end{array}$ & 23 & $\begin{array}{c}34,8 \\
(24,5-46,9)\end{array}$ & 27 & $\begin{array}{c}40,9 \\
(30,0-53,0)\end{array}$ & 0,523 & 0,091 \\
\hline $\begin{array}{l}\text { A sequência recomendada para um } \\
\text { único socorrista é iniciar as } \\
\text { compressões torácicas antes de aplicar } \\
\text { as ventilações de resgate (C-A-B em } \\
\text { vez de A-B-C), para reduzir o tempo até } \\
\text { a primeira compressão }\end{array}$ & 45 & $\begin{array}{c}68,2 \\
(56,2-78,2)\end{array}$ & 56 & $\begin{array}{c}84,8 \\
(74,3-91,3)\end{array}$ & 0,054 & 0,204 \\
\hline
\end{tabular}


A Tabela 4 mostra o efeito da intervenção educativa sobre a prática em RCP realizada durante a atividade (componente 4). Todos os 10 itens analisados (100,0\%) apresentaram melhoria significativa após a intervenção, com o aumento da proporção de conhecimento em todos os itens práticos sobre RCP.

Tabela 4 - Análise do efeito da intervenção educativa sobre RCP nos itens da prática em RCP dos discentes da área da saúde, N=66. Goiânia - GO, 2021.

\begin{tabular}{|c|c|c|c|c|c|c|}
\hline \multirow{2}{*}{ Itens $^{\dagger}$} & \multicolumn{2}{|r|}{ Pré } & \multicolumn{2}{|r|}{ Pós } & \multirow[b]{2}{*}{$p^{\star}$} & \multirow[b]{2}{*}{ Cohen'g } \\
\hline & $\mathbf{n}$ & $\%$ (IC95\%) & $\mathbf{n}$ & $\%(I C 95 \%)$ & & \\
\hline Verificou a segurança do local? & 3 & $\begin{array}{c}4,5 \\
(1,6-12,5) \\
\end{array}$ & 60 & $\begin{array}{c}90,9 \\
(81,5-95,8) \\
\end{array}$ & $<0,001$ & 0,500 \\
\hline $\begin{array}{c}\text { Ligou para o SAMU ou delegou alguém } \\
\text { para ligar? }\end{array}$ & 40 & $\begin{array}{c}60,6 \\
(48,5-71,5) \\
\end{array}$ & 61 & $\begin{array}{c}92,2 \\
(83,5-96,7) \\
\end{array}$ & $<0,001$ & 0,458 \\
\hline $\begin{array}{c}\text { Solicitou ou delegou alguém para buscar } \\
\text { o kit de primeiros-socorros? }\end{array}$ & 1 & $\begin{array}{c}1,5 \\
(0,3-8,1)\end{array}$ & 28 & $\begin{array}{c}43,9 \\
(31,2-54,4)\end{array}$ & $<0,001$ & 0,500 \\
\hline $\begin{array}{c}\text { Chamou a vítima em voz alta e com o } \\
\text { toque ao corpo? }\end{array}$ & 6 & $\begin{array}{c}9,1 \\
(4,2-18,5)\end{array}$ & 58 & $\begin{array}{c}87,9 \\
(77,9-93,7)\end{array}$ & $<0,001$ & 0,500 \\
\hline $\begin{array}{l}\text { Verificou pulso? Ou verificou pulso e } \\
\text { respiração simultaneamente? }\end{array}$ & 29 & $\begin{array}{c}43,9 \\
(32,6-55,9)\end{array}$ & 62 & $\begin{array}{c}93,9 \\
(85,4-97,2)\end{array}$ & $<0,001$ & 0,500 \\
\hline $\begin{array}{l}\text { Iniciou compressão torácica de alta } \\
\text { qualidade? }\end{array}$ & 7 & $\begin{array}{c}10,6 \\
(5,2-20,3) \\
\end{array}$ & 64 & $\begin{array}{c}97,0 \\
(89,6-99,2) \\
\end{array}$ & $<0,001$ & 0,500 \\
\hline Verificou se a vítima voltou da PCR? & 3 & $\begin{array}{c}4,5 \\
(1,6-12,5) \\
\end{array}$ & 46 & $\begin{array}{c}69,7 \\
(57,8-79,5) \\
\end{array}$ & $<0,001$ & 0,500 \\
\hline $\begin{array}{l}\text { Monitorizou a vítima até a chegada do } \\
\text { SAMU? }\end{array}$ & 3 & $\begin{array}{c}4,5 \\
(1,6-12,5)\end{array}$ & 59 & $\begin{array}{c}89,4 \\
(79,7-94,8)\end{array}$ & $<0,001$ & 0,500 \\
\hline $\begin{array}{l}\text { Realizou todas as etapas na ordem } \\
\text { correta? }\end{array}$ & 1 & $\begin{array}{c}1,5 \\
(0,3-8,1)\end{array}$ & 22 & $\begin{array}{c}33,3 \\
(23,2-45,3)\end{array}$ & $<0,001$ & 0,500 \\
\hline
\end{tabular}

Legenda: IC95\%=Intervalo de Confiança de 95\%; RCP=Reanimação Cardiopulmonar; PCR=Parada Cardiorrespiratória; *Teste de McNemar, †Representa a proporção de acertos dos discentes (\%) e IC95\%.

Fonte: Marinho TA, et al., 2021.

A Tabela 5 sintetiza a análise do efeito do treinamento nos componentes do conhecimento avaliados. Verificou-se aumento significativo do grau do conhecimento em todos os componentes com tamanho de efeito grande, assim como o conhecimento global dos estudantes: Teoria-PCR $(72,1 \%$ para $82,7 \%$; $d=0,743)$, Teoria-DEA (52,5\% para 80,3\%; $d=1,134)$, Teoria-RCP $(60,0 \%$ para $78,6 \%$; $d=1,397)$; Prática $(15,7 \%$ para $77,9 \% ; d=3,445)$ e Conhecimento global $(50,1 \%$ para $79,9 \% ; d=2,549)$.

Tabela 5 - Análise do efeito do treinamento em RCP nos componentes do conhecimento em discentes da área da saúde, N=66. Goiânia - GO, 2021.

\begin{tabular}{lcccccc}
\hline Itens $^{\dagger}$ & \multicolumn{2}{c}{ Pré } & \multicolumn{2}{c}{ Pós } & & \\
\cline { 2 - 5 } & $\boldsymbol{M}$ & $\mathbf{I C 9 5 \%}$ & $\boldsymbol{M}$ & $\mathbf{I C 9 5 \%}$ & $\boldsymbol{p}^{*}$ & Cohen'd \\
\hline Teoria & & & & & & \\
PCR & 72,1 & $68,7-75,5$ & 82,7 & $79,3-86,1$ & $<0,001$ & 0,743 \\
DEA & 52,5 & $46,1-59,0$ & 80,3 & $74,7-85,9$ & $<0,001$ & 1,134 \\
RCP & 60,0 & $56,8-63,2$ & 78,6 & $75,3-82,0$ & $<0,001$ & 1,397 \\
\hline Prática & 15,7 & $11,9-19,4$ & 77,9 & $73,0-82,9$ & $<0,001$ & 3,445 \\
\hline Global & 50,1 & $47,6-52,5$ & 79,9 & $76,7-83,1$ & $<0,001$ & 2,549 \\
\hline
\end{tabular}

Legenda: IC95\%=Intervalo de Confiança de 95\%; PCR=Parada Cardiorrespiratória; DEA=Desfibrilador Externo Automático; RCP=Reanimação Cardiopulmonar; M=Média; *Teste t de Student para amostras pareadas; †Grau de conhecimento expresso em Média (IC95\%).

Fonte: Marinho TA, et al., 2021. 


\section{DISCUSSÃO}

Em relação aos dados sociodemográficos, a média de idade dos participantes foi acima de 18 anos, correlacionando esse dado com a distribuição por cursos, a maior parte dos estudantes pertencia ao curso Técnico de Enfermagem, ofertado na instituição estudada na modalidade EJA. Ainda, o maior percentual de estudantes do curso Técnico de Enfermagem é semelhante ao encontrado em outro estudo realizado com discentes de cursos técnicos da saúde (AMORIM CSV, et al., 2018). A maioria era do sexo feminino, tal dado assemelha-se ao encontrado em outras pesquisas com estudantes da saúde (CHAVES ECL, et al., 2015; SANTOS TCMM, et al., 2016).

Não possuir cônjuge foi relato da maior parte dos estudantes, assim como verificado em escola pública profissionalizante em Minas Gerais (MATOS JF, et al., 2018). Os demais dados sociodemográficos: se autodeclarar pardo e renda familiar média entre 1 a 2 salários mínimos foram observados em estudantes do curso técnico de enfermagem na Bahia (RODRIGUES AS, et al., 2015).

Os resultados do conhecimento teórico dos discentes nesta pesquisa, nos levam a inferir que houve melhora na aprendizagem pós intervenção teórica, frente a identificação da PCR $(p=0,002)$, frequência e profundidade da compressão torácica ( $p=<0,001$ e 0,002$)$, posicionamento correto das mãos $(p=0,016)$, além do intervalo das compressões $(p=0,004)$, itens verificados através da avaliação do componente 1 (conhecimento teórico relativo a PCR). Resultados semelhantes foram encontrados em uma instituição de ensino em São Paulo, com ingressantes de cursos da área da saúde, verificada por Avaliação do Conhecimento (teoria) frente às manobras de RCP após aula teórica e demonstração prática (KAWAKAME $P$ e MIYADAHIRA A, 2015).

Conforme as diretrizes da AHA, a avaliação inicial da vítima em PCR inclui a rápida identificação dos sinais clínicos. Assim, a primeira conduta é a avaliação da resposta da vítima, ausência de pulso e respiração em 10 segundos (AHA, 2019). No presente estudo 83,3\% (IC: 72,6-90,4) responderam corretamente pré intervenção educativa e esse número subiu para $98,5 \%$ (IC: 91,9-99,7) após a atividade. Em outro estudo realizado em São Paulo, que avaliou o conhecimento dos graduandos de enfermagem sobre SBV, apenas $55 \%$ dos estudantes responderam corretamente aos questionamentos (OLIVEIRA SS, et al., 2014). O déficit de conhecimento na temática foi identificado posteriormente à formação, abrangendo também profissionais da saúde (SANTOS RP, et al., 2017). Tais dados ratificam a importância de atividades de capacitação, treinamento e educação continuada sobre RCP, mesmo para profissionais que já atuam na área da saúde.

Além da identificação da PCR, através da detecção precoce de sinais clínicos, a AHA reforça a ênfase nas compressões torácicas efetivas (AHA, 2019). De acordo com a literatura, é apontado conhecimento frágil na qualidade das compressões torácicas entre estudantes da área da saúde, reforçando a importância de intervenções educativas práticas de RCP com ênfase em compressões torácicas de alta qualidade, conforme as recomendações da AHA, como a realizada no presente estudo (CAVEIÃO C, et al., 2017).

A qualidade das compressões torácicas inclui o posicionamento correto das mãos, sobrepostas sobre o terço inferior do osso esterno (AHA, 2019) e ao serem questionados, 87,9\% (IC: 77,9-93,7) dos participantes obtiveram êxito na resposta. Dado compatível com o percentual de $93,8 \%$ de acertos observado em acadêmicos de enfermagem e superior aos $63,6 \%$ encontrado nessa mesma população de estudo, respectivamente (SILVA DV, et al., 2015; RESENDE RT, 2019). A divergência dos dados na literatura reflete a importância do ensino de RCP com ênfase em compressões torácicas de alta qualidade em momentos que reforcem teoria e prática para os discentes.

Quanto ao componente 2 (conhecimento teórico relativo ao DEA), todos os itens abordados apresentaram aumento significativo de acertos se comparado pré e pós intervenção educativa. Ainda assim, requer atenção a dificuldade encontrada em reconhecer que todo socorrista leigo precisa de treinamento para manusear DEA com 7,6\% (IC: 3,3-16,5) de acertos anteriores a intervenção e 51,5\% (IC: 39,7-63,2) após a mesma. Diversos estudantes e leigos relataram receio em utilizar o DEA devido ao medo de infecção, choque, consequências legais e risco de prejudicar a vítima, apesar disso, é notório a existência de barreiras para a introdução de programas de treinamento sobre o DEA nas instituições de ensino, particularmente envolvendo disponibilidade de custeio e carga horária curricular (FERNANDES JM, et al., 2014; MOSESSO VN, 2013). 
Quando questionados sobre a necessidade de choque para reanimação, os estudantes mostraram um aumento significativo de conhecimento: $81,8 \%$ de acertos pré (IC: $70,9-89,3)$ e 93,9\% (IC: 85,4-97,2) pós intervenção educativa ( $p=0,039)$, sendo considerado um bom desempenho. Sabe-se que o choque é indicado para casos em fibrilação ventricular (FV) e taquicardia ventricular sem pulso (TVSP), sendo que esses ritmos podem ser detectados pelo próprio equipamento, e a aquisição desse conhecimento facilita a segurança para o uso do DEA (BERNOCHE C, et al., 2019; GONZALEZ MM, et al., 2013).

Sobre o componente 3 (conhecimento teórico relativo a técnica de RCP), nota-se que neste estudo houve aumento expressivo de acertos na ordem correta da RCP pré 3,0\% (IC: 0,8-10,4) e pós 53\% (IC: 41,2-64,6) $(p<0,001)$ intervenção educativa. Assim como, observado em estudo internacional, onde o treinamento em SBV para ingressantes do curso de medicina motivou e contribuiu para a melhoria do desempenho geral (PANDE S, et al., 2014). Contudo, quase metade dos participantes deste estudo não souberam informar a ordem correta de execução da RCP mesmo após a exposição teórico-prática. Tal achado, é concordante com outra pesquisa, também em estudantes do ensino médio, que mostrou maior dificuldade de aprendizado na sequência correta de ações a serem realizadas durante a RCP (COSTA LL, et al., 2020). Sugerimos que atividades envolvendo RCP possuam maior carga horária, especialmente prática, promovendo um ambiente realístico e dinâmico, favorável para o processo ensino-aprendizagem.

A priorização de compressões torácicas em RCP conduzida por socorrista leigo, com frequência de 100 a 120 compressões por minuto, é determinante para a sobrevivência da vítima (AHA, 2015; AHA 2019; BERNOCHE C, et al., 2019; GONZALEZ MM, et al., 2013). Os dados mostram que esta informação foi, indubitavelmente, assimilada pelos participantes na proporção de acertos, apresentando significância com relação: a importância do número de compressões aplicadas ( $p<0,001)$; a desmistificação de que a ventilação excessiva é necessária para o sucesso da RCP $(p<0,001)$ e a priorização das compressões em detrimento às ventilações $(p=0,039)$. Estudos conduzidos em população semelhante também obtiveram aumento considerável de acertos nos quesitos "compressões torácicas" e "ventilação" (CHAVES AFL, et al., 2017; COSTA LL, et al., 2020; FERNANDES JM, et al., 2014). Além disso, foi evidenciado aprendizado significativo destas variáveis após o treinamento de estudantes de cursos superiores da saúde (KAWAKAME P e MIYADAHIRA A, 2015).

De acordo com a Sociedade Brasileira de Cardiologia, antes do início da RCP é de extrema importância a avaliação da segurança da cena, certificar-se de que o local é seguro reduz a possibilidade novas vítimas (BERNOCHE C, et al., 2019; GONZALEZ MM, et al., 2013). Ao responder o questionamento sobre a segurança do local, os participantes da atual pesquisa apresentaram melhoria significativa, com o aumento de acertos pré $(56,1 \%)$ (IC: 44,1-67,4) e pós (92,4\%) (IC: 83,5-96,7) (p<0,001) atividade educativa, sinalizando ótimo desempenho dos estudantes. Discentes do ensino médio de Maceió-AL possuíam conhecimento prévio inadequado, e ao participarem de uma capacitação sobre SBV, demonstraram também aumento considerável em relação a temática (FERNANDES JM, et al., 2014).

Caso a vítima não responda à avaliação inicial, é imprescindível que o socorrista chame por ajuda e acione o Serviço de Atendimento Móvel de Urgência (SAMU) (AHA, 2019; BERNOCHE C, et al., 2019). Apesar de não haver significância estatística na proporção de acertos $(p=0,250)$, notou-se que 95,5\% (IC: 87,5-98,4) dos participantes acertaram o questionamento pré e 100\% (IC: 94,5-100) pós intervenção educativa, inferindo-se que todos os participantes têm ciência da importância do acionamento do SAMU. Esse achado é semelhante a outras investigações em estudantes do ensino médio, onde foi verificado $100 \%$ de respostas corretas sobre o tema e aumento substancial na porcentagem de acertos pós a capacitação, respectivamente (CHAVES AFL, et al., 2017; COSTA LL, et al., 2020).

Observou-se que apesar de algumas informações não terem apresentado significância para o conhecimento quando comparadas as etapas pré e pós-intervenção educativa, houve considerável aumento ou manutenção de acertos em todas as questões abordadas, evidenciando a atividade educativa como eficiente estratégia de promoção do conhecimento sobre RCP junto aos estudantes de cursos técnicos da saúde integrados ao ensino médio. Corroborando estes achados, outros dois estudos conduzidos entre discentes de ensino médio mostraram importante melhora no desempenho geral sobre RCP nos participantes 
(COSTA LL, et al., 2020; FERNANDES JM, et al., 2014). Crescimento semelhante no desempenho geral sobre RCP também foi verificada em ingressantes de cursos de graduação da área de saúde (KAWAKAME P e MIYADAHIRA A, 2015),

Quanto à avaliação do componente 4 (aplicação do conhecimento teórico e execução da prática), é notório o desempenho positivo após a intervenção educativa para identificação da PCR e treinamento das manobras de RCP. Assim, as variáveis do reconhecimento inicial de PCR obtiveram significância estatística $(p<0,001)$ ao se comparar o pré e pós intervenção: chamar em voz alta e com o toque ao corpo 9,1\% (IC: 4,2-18,5) para 87,9\% (IC: 77,9-93,7), verificação de pulso, ou pulso e respiração simultaneamente 43,9\% (IC: 32,6-55,9) para 93,9 (IC: 85,4-97,2) e o início das compressões torácica de alta qualidade 10,6\% (IC: 5,2-20,3) para $97,0 \%(89,6-99,2)$.

Foi identificado também, índice elevado no alcance de execução nas variáveis: verificou se a vítima voltou da PCR de 4,5\% (IC:1,6-12,5) para 69,7\% (IC:57,8-79,5) e monitorizou a vítima até a chegada do SAMU de 4,5\% (IC:1,6-12,5) para 89,4\% (IC:79,7-94,8). Assim, o desempenho dos participantes, como em outro estudo registrou melhora significativa nas atividades práticas simuladas $(p<0,001)$ em todos os itens avaliados (MEIRA JÚNIOR LE, et al., 2016).

No que se refere a média global, foi evidenciado aumento do conhecimento após o treinamento com simulação realística. Percebe-se que houve diferença média ou grande em relação aos quatro aspectos observados e descritos anteriormente. O efeito na média global foi importante sendo 50,1\% (IC: $47,6-52,5$ ) pré intervenção educativa e 79,9\% (IC: 76,7-83,1) após. Assim, atividade ofertada se mostrou efetiva no que se refere a melhora do conhecimento teórico-prático em situações de PCR, resultado semelhante ao encontrado na literatura (BACHUR CK, et al., 2019).

Treinamentos com simulação realística e outras metodologias ativas são importantes para os estudantes de cursos técnicos da saúde, visto que colaboram na aquisição de conhecimento teórico-prático, garantem maior confiança em ambientes de estágio e, por conseguinte, na prática profissional após a formação (SAMPAIO GB, et al., 2019). Para além do atendimento em urgência e emergência, contribui para a formação de multiplicadores em saúde, vislumbrando as diversas de situações de ocorrências cotidianas de PCR (BARBOSA GS, et al., 2019).

\section{CONCLUSÃO}

O estudo apresentou limitações, dentre elas: tamanho amostral e população restrita à determinadas áreas de formação em saúde. Evidenciou-se melhora no conhecimento dos estudantes no presente estudo após intervenção educativa sobre RCP. Capacitações objetivando atingir pontos susceptíveis no conhecimento acerca da RCP são necessárias desde o início da formação; desenvolvendo habilidades e segurança nos profissionais de saúde e minimizando eventos adversos em situações de RCP. A presente intervenção educativa fornece subsídios para a implementação de programas institucionais na temática. São escassos investigações sobre este assunto na literatura, sugere-se a realização estudos com maior número amostral e diversidade de áreas de formação em saúde.

\section{REFERÊNCIAS}

1. AHA. American Heart Association. Destaques da American Heart Association: Atualização das Diretrizes de RCP e ACE; 2015.

2. AHA. American Heart Association. Destaques das Atualizações Direcionadas nas Diretrizes de 2019 da American Heart Association para Ressuscitação Cardiopulmonar e Atendimento Cardiovascular de Emergência; 2019.

3. AMORIM CSV, et al. Higiene das mãos e prevenção da influenza: conhecimento de discentes da área da saúde. Texto \& Contexto Enfermagem, 2018; 27(4): e4570017.

4. BACHUR CK, et al. Avaliação do conhecimento dos estudantes sobre o procedimento de ressuscitação cardiorrespiratória: uma intervenção educativa. Revista Eletrônica Acervo Saúde (REAS), 2019; 26(1): 1-6.

5. BARBOSA GS, et al. Eficácia da simulação na autoconfiança de estudantes de enfermagem para ressuscitação cardiopulmonar extra-hospitalar: um estudo quase experimental. Sci Med, 2019; 29(1): e32694.

6. BERNOCHE C, et al. Atualização da Diretriz de Ressuscitação Cardiopulmonar e Cuidados de Emergência da Sociedade Brasileira de Cardiologia - 2019. Arq Bras Cardiol, 2019; 113(3): 449-663. 
7. CAVEIÃO C, et al. Conhecimento de acadêmicos de enfermagem acerca das diretrizes de reanimação cardiopulmonar no suporte básico de vida para adultos. Rev Ciên Saúde, 2017; 2(3): 1-7.

8. CHAVES AFL, et al. Reanimação cardiopulmonar nas escolas: avaliação de estratégia educativa. Revista Ex Cat Saúde, 2017; 2(1): 65-72.

9. CHAVES ECL, et al. Anxiety and spirituality in university students: a cross-sectional study. Rev Bra Enferm, 2015; 68(3): 504-509.

10. CITOLINO FILHO CM, et al. Fatores que comprometem a qualidade da ressuscitação cardiopulmonar em unidades de internação: percepção do enfermeiro. Rev. esc. enferm. USP, 2015; 49(6): 907-913.

11. COSTA LL, et al. Cardiopulmonary Resuscitation: educational strategies for public network high school students in the municipality of Maraba - Pará. Braz J of Develop, 2020; 6(2): 9230-9238.

12. FERNANDES JM, et al. Teaching basic life support to students of public and private high schools. Arq Bras Cardiol, $2014 ; 102(6):$ 593-601.

13. FOWLER R, et al. Evolution and revolution in cardiopulmonary resuscitation. Curr Opin Crit Care, 2017; 23(3): 183187.

14. GONZALEZ MM, et al. I Diretriz de Ressuscitação Cardiopulmonar e Cuidados Cardiovasculares de Emergência da Sociedade Brasileira de Cardiologia. Arq Bras Cardiol, 2013; 101(2, Suppl. 3): 1-221.

15. KAWAKAME P, MIYADAHIRA A. Assessment of the teaching-learning process in students of the health area: cardiopulmonary resuscitation maneuvers. Rev Esc Enferm USP, 2015; 49(4): 657-664.

16. MATOS JF, et al. Prevalência, perfil e fatores associados à automedicação em adolescentes e servidores de uma escola pública profissionalizante. Cad. saúde colet, 2018; 26(1): 76-83.

17. MEIRA JÚNIOR LE, et al. Avaliação de treinamento em suporte básico de vida para médicos e enfermeiros da atenção primária. Rev Bras Med Fam Comunidade, 2016; 11(38): 1-10.

18. MONSIEURS KG, et al. European Resuscitation Council Guidelines for Resuscitation 2015: Section 1. Executive summary. Resuscitation. 2015 Oct; 95:1-80.

19. MORAIS FILHO LA, et al. Strategies used for teaching urgency/emergency in a nursing undergraduate course. Texto Contexto Enferm, 2018; 27(4): e3210016.

20. MOSESSO VN. AEDs in schools: lessons learned and to be learned. Resuscitation, 2013; 84(4): 401-2.

21. OLIVEIRA SS, et al. Suporte Básico de Vida: avaliação do conhecimento dos graduandos de enfermagem. J Health Sci Inst, 2014; 32(1): 53-58.

22. ONAN A, et al. A review of simulation-enhanced, team-based cardiopulmonary resuscitation training for undergraduate students. Nurse Educ Pract, 2017; 27: 134-143.

23. PANDE S, et al. Evaluation of retention of knowledge and skills imparted to first-year medical students through basic life support training. Adv Physiol Educ, 2014; 38(1): 42-5.

24. RESENDE RT, et al. Conhecimento dos acadêmicos de enfermagem sobre suporte básico de vida. Rev enferm UFPE on line, 2019; 13(5): 1231-6.

25. RODRIGUES AS, et al. Estudantes de curso técnico de enfermagem sob a perspectiva de gênero. Rev enferm UFPE on line, 2015; 9(5): 8361-7.

26. SAMPAIO GB, et al. Educação Permanente e o Processo Formativo dos Profissionais da Saúde: Entrelace de Saberes. Revista Eletrônica Acervo Saúde (REAS), 2019; 25: e630.

27. SANTOS RP, et al. Intervenção educativa sobre parada cardiorrespiratória intra-hospitalar: conhecimento dos profissionais de enfermagem de unidades médico-cirúrgica. Rev Eletr Enf, 2017; 19: a25.

28. SANTOS TCMM, et al. Sleep quality and chronotype of nursing students Sleep quality and chronotype of nursing students. Acta Paul Enferm, 2016; 29(6): 658-63.

29. SILVA DV, et al. Conhecimento de graduandos em enfermagem sobre suporte básico de vida. Revista Baiana de Enfermagem, 2015; 29(2): 125-134.

30. SILVA WM, et al. Eventos adversos e segurança do paciente no atendimento de urgência e emergência pré-hospitalar. Revista Eletrônica Acervo Saúde (REAS), 2020; 12(9): e4057.

31. YAN S, et al. The global survival rate among adult out-of-hospital cardiac arrest patients who received cardiopulmonary resuscitation: a systematic review and meta-analysis. Crit Care, 2020; 24(1): 61. 